\title{
Development of the Technology for Processing Plant Breeding By-Products to Obtain Biosorbent
}

\author{
Tatiana Bauer 1,*, Svetlana Sushkova ${ }^{2}$, Aleksei Fedorenko ${ }^{1,2}$, Ilya Lobzenko ${ }^{2}$, Anatoly \\ Barakhov $^{1}$, Vera Butova ${ }^{1}$, and Ekrem Tuşat ${ }^{3}$ \\ ${ }^{1}$ Federal Research Center the Southern Scientific Center of the Russian Academy of Sciences, 344006 \\ Rostov-on-Don, Russian Federation \\ ${ }^{2}$ Southern Federal University, Academy of Biology and Biotechnology, 344090 Rostov-on-Don, \\ Russian Federation \\ ${ }^{3}$ Konya Technical University, Department of Geomatics Engineering, 42075 Konya, Turkey
}

\begin{abstract}
This study focuses on the potential transforming sunflower husk wastes into innovative green products to be used for the recultivation of contaminated soils. This transformation makes it possible to utilize the large quantity plant breeding by-products to obtain a highly porous biosorbent. Optimal conditions for the preparation of bisorbents can be determined based on measurements of their specific surface and porosity. It is shown that structural characteristics of sorbent depend on conditions of the pyrolysis of primary raw material. Optimal conditions for obtaining biosorbent with a specified proportion of meso- and micropores and high specific surface are performed under three-stage pyrolysis as given by following conditions: sample holding time of 10-30 min, final temperature $700^{\circ} \mathrm{C}$, and heating rate $15^{\circ} \mathrm{C} / \mathrm{min}$. A 3-month incubation study was conducted to investigate its performance in stabilization of copper contamination in Fluvisol. The sequential extraction procedure showed that the $1 \%$ sunflower husks biosorbent treatment reduced the mobile pool (exchange and carbon-bonded fractions) of $\mathrm{Cu}$ from 8 to $4 \%$, respectively, compared to the contaminated soil. $\mathrm{Cu}$ is found to be tightly bonded owing to the increase of the residual and organic matter-bonded metal fractions. Owing to its adsorptive properties, biosorbent amendment of coppercontaminated soils appears as a promising approach to reduce the pollutant mobility and bioavailability.
\end{abstract}

\section{Introduction}

At present, huge amounts of renewable plant-related wastes and reworking products of carbon-containing raw material are produced every year in the world [1]. Therefore, a rational solution to their utilization with the simultaneous recovery of upgraded products is an urgent issue $[2,3]$.

\footnotetext{
* Corresponding author: bauertatyana@mail.ru
} 
It is interesting to note that huge amounts of wastes are accumulated currently in each region based on the cultivation and production of organic feedstock. In particular, vast (tonnage-scale) source of wastes leftover after the reworking of sunflower husk are available now in the Rostov region (southern European part of Russia). On the average, their accumulation rate is as much as 300 thou ton/year, and this value is growing each year due to intensification of the production of oilseeds. This huge potential, however, is not fully exploited (not more than $25-30 \%$ ) because due to a lack of economic and efficient waste utilization technologies. Some part of the waste is used for the production of fuel briquettes, but a major part is dumped, resulting in economic inefficiency and ecological hazards [4].

Promising methods are considered shifting towards technologies that facilitate the reworking of plant biomass into biochar (biosorbent). Currently, biochar is widely applied for the amelioration and remediation of soils subjected to technogenic pollution $[5,6]$. Biochar commonly is obtained by the pyrolysis of plant waste in an inert atmosphere. In this process, the composition of primary raw material and conditions of its pyrolysis are of the crucial factors that control parameters of the pore structure of sorbent [7]. Among these parameters, the maximum temperature of biomass treatment in the pyrolysis reactor exerts the greatest influence on the properties of the produced biochar [8]. The lower the pyrolysis temperature, the lesser the percentage content of carbon and the degree of its aromatization in the final product. The pyrolysis duration shows an inverse correlation with the amount of water and oxygen-containing compounds in the ultimate product. Moreover, the end product is characterized by high acidity and low thermal stability [7].

Studies of the remediation of $\mathrm{Cu}$-contaminated soil are particularly important. Copper is a priority pollutant of soils in southern Russia [9, 10]. High technical applicability of copper and its extensive use in different industrial fields are responsible for the soil pollution with this metal. The release of $\mathrm{Cu}$ compounds to riverine systems can result in extensive accumulations of metal in surrounding riverbank sediment and floodplain soils. The remediation of floodplain soils polluted with heavy metals such as $\mathrm{Cu}$ is necessary for mitigating their environmental and human health risk. The complexity of the soil formation process, its high dynamism, the specifics of water supply, the significant influence of intrazonal factors are the main reasons for the poor knowledge of the floodplain soils detoxification methods.

The aim of the present work is to develop a technology for obtaining highly porous biosorbent from the sunflower husk waste to recultivate the $\mathrm{Cu}$ contaminated soils.

\section{Materials and Methods}

Experimental biochar samples were obtained by the thermal decomposition of sunflower husk based on the variation of temperature $\left(300^{\circ}, 500^{\circ}, 700^{\circ}, 900^{\circ} \mathrm{C}\right.$ ), heating rate (from 5 to $30{ }^{\circ} \mathrm{C} / \mathrm{min}$ ) and hold period (from 10 to $75 \mathrm{~min}$ ) of biomass. For this purpose, the primary raw material was subjected to a steel retort that was hermetically sealed with a welded flange for gas removal and placed in a muffle furnace, supplying the vessel with nitrogen to create an inert atmosphere. The vessel was heated in several stapes with a specified temperature increase rate and incubated at the desired heating temperature for 1075 min. After termination of the calcination, the vessel was cooled down to room temperature and the obtained biochar was unloaded. Then, the chemical composition, physicochemical properties and structural characteristics were determined.

The yield of biosorbent per dry mass of primary raw material was calculated according to the following formula [11]:

$$
M_{b} /\left[M_{r}\left(1-W_{r} / 100\right)\right] 100, \%
$$


where $M_{b}$ is the yield of biosorbent, $\mathrm{g} ; M_{r}$ is the weighed portion of the primary raw material, $\mathrm{g}$; and $W_{r}$ is the moisture content in the primary raw material, $\%$.

The specific surface and porosity of the carbon-bearing samples were measured with an ASAP 2020 volumetric analyzer, and micrometric properties were determined by the lowtemperature nitrogen adsorption method. The specific surface and porosity parameters were determined using the $\mathrm{N}_{2}$-based BET specification method in the equilibrium range of $\mathrm{P} / \mathrm{P} 0$ $=0.05-0.97$. Volumes of micro- and mesopores in the sorbents were determined with the relative $t$ method based on the Hurkins-Jura equation for computing thickness of the statistic adsorbate layer [12]. The computation of the pore size distribution was based on the nonlocal density functional theory (NLDFT) [13].

Specific features of the topography (surface) and morphology (microgeometry) of the obtained sorbent fragments were analyzed with a Carl Zeiss EVO-40 XVP scanning electron microscope under the standard conditions (for nonconducting low-contrast samples). The microscope analysis was done in a low vacuum, $15 \mathrm{kV}$, and high emission mode.

We accomplished model experiments to study the efficiency of the recultivation of the contaminated soil based on biosorbent. For this purpose, we sampled the upper humus horizon $(0-20 \mathrm{~cm})$ of the clay loamy Fluvisol in the Kamenka district (Rostov region). This soil is characterized by the following physicochemical properties: $\mathrm{C}_{\text {org }} 4.3 \%, \mathrm{pH} 7.5$, exchange cations $\left(\mathrm{Ca}^{2+}+\mathrm{Mg}^{2+}\right) 38.1 \mathrm{cM}(+) / \mathrm{kg}, \mathrm{CaCO}_{3} 0.6 \%$, physical clay fraction (particles $<0.01 \mathrm{~mm}$ ) $55.8 \%$, clay fraction (particles $<0.001 \mathrm{~mm}$ ) $-32.0 \%$, and $\mathrm{Cu} 43.7$ $\mathrm{mg} / \mathrm{kg}$. The pollutant was represented by $\mathrm{Cu}(300 \mathrm{mg} / \mathrm{kg}$ per pure element). Before starting the experiment, soil samples were dried and ground to <1-mm-size particles; plant remains and large inclusions were removed; weighed soil portions (100 g each) were placed into plastic containers; and an aqueous solution of copper acetate was added and thoroughly stirred. After a 2-week-long metal incubation in the soil, the vessels were mixed with $1 \%$ of biochar corresponding approximately to $200 \mathrm{~kg} / 100 \mathrm{~m}^{2}$ or $20 \mathrm{t} / \mathrm{ha}$ if recalculated to the 20 $\mathrm{cm}$-thick topsoil. The experiment was carried out with three-replicate measurements over 3 months. Then, the dry soil was again ground and sieved (pore size $1 \mathrm{~mm}$ ) for further analyses. Analogous procedures but without addition of metal and biosorbent were performed with the control sample. In the course of the entire experiment, optimal moisture content (60\% of the total moisture capacity) was maintained in the vessels. The contaminated soil was incubated at room temperature and natural lighting.

The composition of Cuu compounds in soil was determined using the sequential fractionation method proposed by Tessier et al. [14]. This method allows extracting five fractions of metal compounds: exchange $\left(1 \mathrm{M} \mathrm{MgCl}_{2}\right)$ related with carbonates (1M $\mathrm{CH}_{3} \mathrm{COONa}$ ), Fe-Mn (hydr)oxides $\left(0.04 \mathrm{M} \mathrm{NH} \mathrm{N}_{2} \mathrm{OH} \cdot \mathrm{HCl}\right.$ in $\left.25 \% \mathrm{CH}_{3} \mathrm{COOH}\right)$, organic matter $\left(0.02 \mathrm{M} \mathrm{HNO}_{3}+30 \% \mathrm{H}_{2} \mathrm{O}_{2}\right.$, pH 2, then $3.2 \mathrm{M} \mathrm{CH}_{3} \mathrm{COONH}_{4}$ in $\left.20 \% \mathrm{HNO}_{3}\right)$ and residual $\left(\mathrm{HF}+\mathrm{HClO}_{4}\right.$, then $\mathrm{HNO}_{3}$ conc.) fractions. The $\mathrm{Cu}$ content in leachates was determined by the atomic absorption spectrometry with a Kvant-2AT AAS.

\section{Results and Discussion}

Processing of the sunflower husk samples at the different temperature, heating rate and hold period gave the following results: yield of biochar 13-29\%, moisture content 1-6\%, yield of volatile matter $7-23 \%$, carbon content $60-89 \%$, ash content $0.5-12.7 \%$, and $\mathrm{pH} 7.1-9.6$. In this process, pyrolysis exerted a significant influence on the structure and properties of the obtained biosorbents. Parameters of the pore structure of biochars obtained from the sunflower husk are presented in Table 1. In all studied range of heating rate and hold period $(10-45 \mathrm{~min})$ at the final heating temperature $\left(300^{\circ} \mathrm{C}\right)$, the specific surface of biochar samples computed from the BET method is characterized by small values: $5-40 \mathrm{~m}^{2} / \mathrm{g}$. The 
increase of the final temperature to $700^{\circ} \mathrm{C}$ fosters an appreciable growth of the specific surface to $660 \mathrm{~m}^{2} / \mathrm{g}$ depending on the heating rate and hold period. The total volume of pores in sorbents varies from 0.47 to $0.89 \mathrm{~cm}^{3} / \mathrm{g}$ (Table 1).

Table 1. Parameters of the pore structure of biosorbent samples recorded at different conditions of pyrolysis.

\begin{tabular}{|c|c|c|c|c|}
\hline $\begin{array}{c}\mathbf{S S A}, \\
\mathbf{m}^{2} / \mathbf{g}\end{array}$ & $\mathbf{V}_{\Sigma}, \mathbf{c m}^{\mathbf{3}} / \mathbf{g}$ & $\begin{array}{c}\mathbf{V}_{\text {micro }} \\
(>\mathbf{2} \mathbf{~ n m}), \\
\mathbf{c m}^{\mathbf{3}} \mathbf{g}\end{array}$ & $\begin{array}{c}\mathbf{V}_{\text {meso }} \\
(\mathbf{2 - 5 0 0} \mathbf{~ n m}), \\
\mathbf{c m}^{\mathbf{3}} / \mathbf{g}\end{array}$ & $\begin{array}{c}\mathbf{V}_{\text {macro }} \\
(>\mathbf{5 0 0} \mathbf{~ n m}), \\
\mathbf{c m}^{\mathbf{3}} \mathbf{g}\end{array}$ \\
\hline $5-660$ & $0.47-0.89$ & $0.12-0.63$ & $0.04-0.19$ & $0.09-0.31$ \\
\hline
\end{tabular}

SSA: specific surface area $\left(\mathrm{m}^{2} / \mathrm{g}\right) ; \mathrm{V}_{\Sigma}$ : total pore volume $\left(\mathrm{cm}^{3} / \mathrm{g}\right) ; \mathrm{V}_{\text {micro }}$ : micropore volume $\left(\mathrm{cm}^{3} / \mathrm{g}\right)$; $\mathrm{V}_{\text {meso }}$ : mesopore volume $\left(\mathrm{cm}^{3} / \mathrm{g}\right) ; \mathrm{V}_{\text {macro: }}$ macropore volume $\left(\mathrm{cm}^{3} / \mathrm{g}\right)$.

Based on electron microscopy, the studied biochar samples are marked by heterogeneity in terms of the disperse and morphological composition and pore size, depending on the conditions of their production. At the pyrolysis temperature of $300-700^{\circ} \mathrm{C}$, the samples show abundant isometric and elongated pores from 3 to $12 \mu \mathrm{m}$ across. At high final temperature $\left(900^{\circ} \mathrm{C}\right)$ of pyrolysis, the pore structure is distorted: the surface is broken into separate microblocks, with pores between them reaching $38 \mu \mathrm{m}$. They are marked by significant surface alterations that deteriorate the sorption properties of the biochar.

Analysis of structural characteristics of the obtained biochar samples revealed the following point: optimal conditions for their preparation with the specified proportion of micro- and mesopores and the high specific surface can be provided by the three-stage pyrolysis with the sample hold period ranging from 10 to $30 \mathrm{~min}$ at the final temperature of $700^{\circ} \mathrm{C}$ and heating rate of $15^{\circ} \mathrm{C} / \mathrm{min}$. Pyrolysis at $900^{\circ} \mathrm{C}$ seems to be less economic than heating to $700^{\circ} \mathrm{C}$. Moreover, the increase in the sorbent processing temperature provokes not only the pore structure distortion in the sorbent but also the increase in the cancerogenic compounds therein.

For the model experiment a biosorbent with the greatest specific surface was chosen at the optimal conditions of pyrolysis with further properties as follows obtained: moisture content $3.5 \%$, ash content $10.1 \%$, yield of volatile matter $9.6 \%$, carbon content $87 \%$, and $\mathrm{pH}$ 9.0. The studied samples are marked by the following parameters: specific surface area of $660 \mathrm{~m}^{2} / \mathrm{g}$ and total pore volume of $0.81 \mathrm{~cm}^{3} / \mathrm{g}$. The major part of pores $\left(0.63 \mathrm{~cm}^{3} / \mathrm{g}\right)$ is composed of micropores ( $>2 \mathrm{~nm})$.

The results of scanning electron microscopy demonstrated that the studied biosorbent sample is heterogeneous in terms of morphological composition and pore size compared to the characteristics of the primary raw material. The biosorbent particles show the anisotropic structure of pores that represent long cylindrical cavities extending along the longitudinal axis of sunflower husk particles. The sagittal section (Fig. 1a) shows a surface with numerous fractures and slotted pores 1-2 $\mu \mathrm{m}$ wide. The segmentary chip (Fig. 1b) contains numerous rounded pores $(10-30 \mu \mathrm{m})$ and smaller pores $(0.5-1 \mu \mathrm{m})$.

The sequential fractionation of copper compounds in the noncontaminated Fluvisol (Control sample) revealed explicit domination of metal in the residual silicate-related fraction (Table 2). A significant contribution to the robust bonding of $\mathrm{Cu}$ is also made by the soil-hosted organic matter that accounts for $16 \%$ of the total sum of fractions. In the first two fractions marked by the weakest bond with soil, the relative metal content is just $3 \%$. Low mobility and domination of $\mathrm{Cu}$ in the residual fraction suggest the absence of a notable amount of technogenic metal in the background soil. 

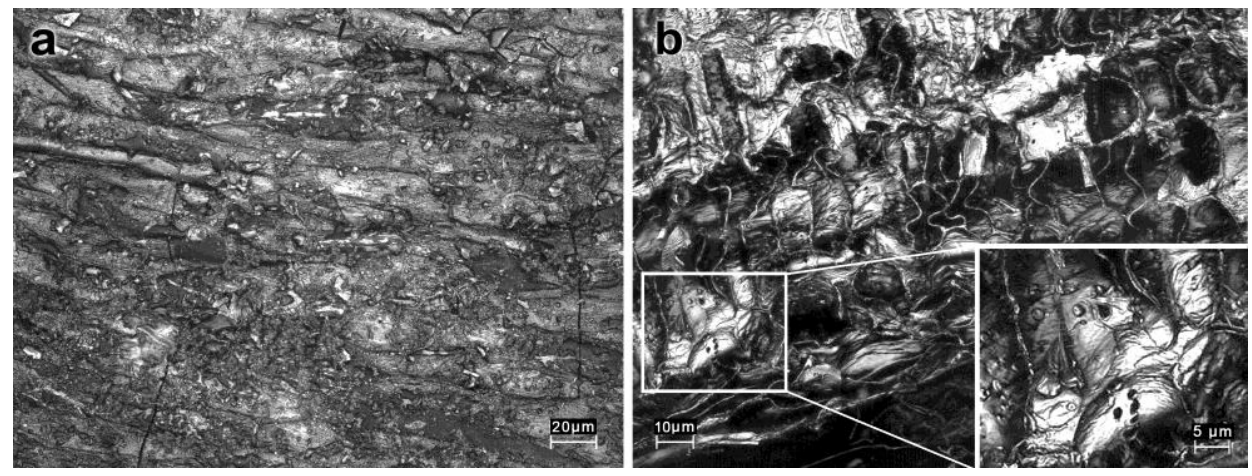

Fig. 1. SEM photomicrographs of the biosorbent: (a) Fragment of sample in the sagittal plane, (b) transverse cleavage.

The increase of the technogenic load $(300 \mathrm{mg} / \mathrm{kg})$ upon soil provokes alteration of the fractional composition of $\mathrm{Cu}$. The share of the residual fraction decreases due to the increase in the relative content of all other metal fractions (Table 2). Analogous reverse correlation between the most conservative residual fraction of $\mathrm{Zn}$ versus the technogenic pollution of soils is also reported in $[15,16]$.

The attenuation of metal mobility was recorded in the experiment performed with the addition of biosorbent. Exchange forms and carbonate-bonded copper species decrease by $2 \%$ (Table 2). In addition to the high specific surface of the carbon-bearing sorbents [17], the alkaline reaction of medium is also responsible for the weakening of metal mobility. For example, the increase of $\mathrm{pH}$ related to the addition of biochar in the $\mathrm{Pb}$-contaminated soils promoted a decrease in the bioavailability of heavy metals and positive influence on microbiological processes [18].

Table 2. Fractional composition of copper compounds in a Fluvisol during the addition of biosorbent.

\begin{tabular}{|c|c|c|c|c|c|c|}
\hline \multirow{2}{*}{ Variant } & \multicolumn{7}{|c|}{$\begin{array}{c}\text { Exactions } \\
\text { eable }\end{array}$} & $\begin{array}{c}\text { Carbonate- } \\
\text { bound }\end{array}$ & $\begin{array}{c}\text { Fe/Mn } \\
\text { hydr)oxi } \\
\text { de-bound }\end{array}$ & $\begin{array}{c}\text { Organic } \\
\text { matter- } \\
\text { bound }\end{array}$ & Residual & Sum \\
\hline \multicolumn{7}{|c|}{$\mathrm{mg} / \mathrm{kg}$} \\
\hline $\mathrm{Control}$ & $0.2 \pm 0.04$ & $1.2 \pm 0.1$ & $3.0 \pm 0.2$ & $6.8 \pm 0.7$ & $32.5 \pm 2.7$ & 43.7 \\
\hline $\mathrm{Cu}$ & $8.7 \pm 0.9$ & $15.9 \pm 1.6$ & $32.4 \pm 4.1$ & $80.3 \pm 6.9$ & $209.7 \pm 23.1$ & 347 \\
\hline $\mathrm{Cu}+$ sorbent & $4.6 \pm 0.7$ & $11.2 \pm 1.0$ & $23.9 \pm 4.2$ & $89.7 \pm 7.5$ & $215.6 \pm 18.4$ & 345 \\
\hline \multicolumn{7}{|c|}{$\%$ of the sum fractions } \\
\hline Control & 0 & 3 & 7 & 16 & 74 & 100 \\
\hline $\mathrm{Cu}$ & 3 & 5 & 9 & 23 & 60 & 100 \\
\hline $\mathrm{Cu}+$ sorbent & 1 & 3 & 7 & 26 & 63 & 100 \\
\hline
\end{tabular}

Similar data are reported elsewhere [19], demonstrating that the addition of biochar obtained from rice straw and bamboo stems for the sandy loam of paddy soil also appreciably decreases concentrations of the mobile $\mathrm{Cu}, \mathrm{Cd}, \mathrm{Pb}$ and $\mathrm{Zn}$ species. The addition of the carbonaceous sorbent to the contaminated soil leads to a $3 \%$ growth of the $\mathrm{Cu}$ content in the organic-related fraction. This trend can be caused by the addition of organic matter to soil that actively absorbs $\mathrm{Cu}$ ions. More than two-thirds of coal is composed of the amorphous carbon, a part of which is burned during pyrolysis with the formation of differently sized pores. It results not only in the development of a large specific absorbing surface, but also in the increment of organic matter in the soil $[20,21]$. The increase of soil organic matter due to biosorbent addition can convert labile $\mathrm{Cu}$ into the less mobile fractions, e.g., organically bound fractions. The functional groups (e.g., $-\mathrm{OH},-\mathrm{COOH}$, 
$-\mathrm{C}=\mathrm{O}-$, and $\mathrm{C}=\mathrm{N}$ ) in biochar provide also binding sites for heavy metals to form complexes, which increase the specific adsorption of metals [22]. The residual fraction content also tends to increase in the experiment with sorbent addition (Table 2). These results suggest a more robust bonding of $\mathrm{Cu}$ in the soil at the presence of a highly porous biosorbent. Treatments of carbonaceous sorbent increased the transformation of the unstable $\mathrm{Cu}$ (exchangeable and carbonate-bound fractions) into stable metal (residual fraction), which had resulted from the elevated $\mathrm{pH}$.

\section{Conclusions}

The technology was developed for the sunflower husk transforming into biosorbent to promote the sustainability and remediate the technogenic contaminated soils. Optimal conditions for the three-stage pyrolysis of the primary raw material were chosen for the preparation of biosorbent with specified proportions of micro- and mesopores and high specific surface. The model experiment demonstrated that the addition of green produced biochar to the contaminated Fluvisol exerts a positive influence on the immobilisation of the mobility $\mathrm{Cu}$ compounds. This is manifested in decrease of the first two most mobile fractions of metal and the increase of the share of $\mathrm{Cu}$ tightly bonded with organic matter and clay minerals. The results demonstrated that the produced biosorbent can effectively immobilize $\mathrm{Cu}$, thereby reducing its mobility in contaminated floodplain soils. This indicated that these amendments can directly transform the highly availability metal speciation to the stable speciation in soils.

The reported study was funded by RFBR, project number 19-34-60041 and Grant of President of Russian Federation, no. MK-2244.2020.5.

\section{References}

1. Y. Dai, Q. Sun, W. Wang, L. Lu, M. Liu, J. Li, S. Yang, Y. Sun, K. Zhang, J. Xu, W. Zheng, Z. Hu, Y. Yang, Y. Gao, Y. Chen, X. Zhang, F. Gao, Y. Zhang, Chemosphere, 211, 235-253 (2018)

2. T. Väisänen, A. Haapala, R. Lappalainen, L. Tomppo, Waste Management, 54, 62-73 (2016)

3. Q. Zhang, D. Zhang, H. Xu, W. Lu, X. Ren, H. Cai, H. Lei, E. Huo, Y. Zhao, M. Qian, X. Lin, E.M. Villota, W. Mateo, Ind Crops Prod., 146, 112185 (2020)

4. K. He, J. Zhang, Y. Zeng, Sci. Total Environ., 670, 236-244 (2019)

5. S. Bashir, M. Shaaban, S. Mehmood, J. Zhu, Q. Fu, H. Hu, Bull. Environ. Contam. Toxicol., 100, 834-838 (2018)

6. M. Zhu, L. Zhang, L. Zheng, Y. Zhuo, J. Xu, Y. He. Front. Microbiol., 9, 579 (2018)

7. M. Ahmad, A.U. Rajapaksha, Ju.E. Lim, M. Zhang, N. Bolan, D. Mohan, M. Vithanage, S.S. Lee, Y.S. Ok, Chemosphere, 99, 19-33 (2014)

8. M. Uchimiya, D.I. Bannon, L.H. Wartelle, I.M. Lima, K.T. Klasson, J. Agric. Food Chem., 60, 5035-5044 (2012)

9. T. Bauer, T. Minkina, D. Pinskii, S. Mandzhieva, S. Sushkova, J. Geochem. Explor., 176, 108-113 (2017)

10. Minkina T, Pinskii D, Bauer T, Nevidomskaya D, Mandzhieva S, Sushkova S, J. Geochem. Explor., 174, 107-112 (2017)

11. J. Velebil, J. Malat’ák, J. Bradna, Res. Agr. Eng., 62 (4), 179-184 (2016) 
12. C. Scherdel, G. Reichenauer, M. Wiener, Microporous Mesoporous Mater., 132 (3), 572-575 (2010)

13. J. Landers, G.Y. Gor, A.V. Neimark, Coll. Surf., A: Physicochem., Eng. Aspects, 437, 3-32 (2013)

14. A. Tessier, P. Campbell, M. Bisson, Anal. Chem., 51, 844-850 (1979)

15. M.V. Burachevskaya, T.M. Minkina, S.S. Mandzhieva, T.V. Bauer, V.A. Chaplygin, S.N. Sushkova, P. Orlović-Leko, L.Yu. Mashtykova, V.D. Rajput, J. Soils Sediments, 18 (6), 2379-2386 (2018)

16. M.T. Nielsen, J.J. Scott-Fordsmand, M.W. Murphy, S.M. Kristiansen, J. Soils Sediments, 15, 1558-1570 (2015).

17. M. Pukalchik, F. Mercl, V. Terekhova, P. Tlustoš, Chemosphere, 203, 228-238 (2018)

18. A.D. Igalavithana, S.E. Lee, Y.H. Lee, D.C. Tsang, J. Rinklebe, E.E. Kwon, Y.S. Ok, Chemosphere, 174, 593-603 (2017)

19. K. Lu, X. Yang, G. Gielen, N. Bolan, Y.S. Ok, N.K. Niazi, S. Xu, G. Yuan, X. Chen, X. Zhang, D. Liu, Z. Song, X. Liu, H. Wang, J. Environ. Manage., 186 (2), 285-292 (2017)

20. D. O'Connor, T. Peng, J. Zhang, D.S.W. Tsang, D.S. Alessi, Z. Shen, N.S. Bolan, D. Hou, Sci. Total Environ., 619, 815-826 (2018)

21. C.S. Lwin, B.H. Seo, H.U. Kim, G. Owens, K.R. Kim, Soil Sci. Plant Nutr., 64 (2), 156-167 (2018)

22. Z. Tan, Y. Wang, L. Zhang, Q. Huang, Environ. Sci. Pollut. Res., 24, 24844-24855 (2017) 